\title{
Prognostic Significance of Pre-treatment Serum C-Reactive Protein Level in Patients with Adenocarcinoma of the Uterine Cervix
}

\author{
BARBARA BODNER-ADLER ${ }^{1}$, OLIVER KIMBERGER ${ }^{2}$, CORA SCHNEIDINGER ${ }^{1}$, \\ HEINZ KÖLBL ${ }^{1}$ and KLAUS BODNER ${ }^{1}$ \\ Departments of ${ }^{1}$ General Gynaecology and Gynaecologic Oncology, and \\ ${ }^{2}$ Anaesthesiology, Medical University of Vienna, Vienna, Austria
}

\begin{abstract}
Aim: To evaluate pre-treatment serum $C$-reactive protein $(C R P)$ level as a prognostic parameter in patients with adenocarcinoma of the uterine cervix. Materials and Methods: Pre-treatment CRP levels were analyzed to determine potential associations with clinicopathological parameters and to assess prognostic value in 46 patients with sole adenocarcinoma of the uterine cervix. Results: The mean $( \pm S D)$ pre-treatment serum CRP level was 5.82 (7.21) $\mathrm{mg} / \mathrm{l}$. Serum CRP concentration significantly correlated positively with age at diagnosis $(p=0.001)$, lymphovascular space invasion $(p=0.0026)$, recurrent disease $(p=0.0001)$ and International Federation of Gynecology and Obstetrics (FIGO) stage $(p=0.0002)$. In multivariate Cox regression models with age, FIGO stage, histological grade and lymph node status, elevated CRP and cancer antigen 125 levels were associated with shortened survival $(p<0.05)$. Overall 5-year survival rate of patients with pre-treatment serum CRP level $<5.0 \mathrm{mg} / \mathrm{l}$ was $100 \%$ compared to $46.9 \%$ for patients with pre-treatment CRP level $\geq 5.0 \mathrm{mg} / \mathrm{l}$. Conclusion: Serum CRP level can be seen as an additional independent prognostic parameter in patients with the rare histological subtype adenocarcinoma of the uterine cervix.
\end{abstract}

Cervical cancer is the third most common cancer in women worldwide, with peak incidence in the 40- to 45-year age group (1). Adenocarcinoma of the uterine cervix is a rare

This article is freely accessible online.

Correspondence to: Barbara Bodner-Adler, MD, Associate Professor, Department of General Gynaecology and Gynaecologic Oncology, Währinger Gürtel 18-20, 1090 Vienna, Austria. Tel: +43 14040029150, Fax: +43 14040029110, e-mail: Barbara.BodnerAdler@meduniwien.ac.at

Key Words: Pre-treatment C-reactive protein level, adenocarcinoma of uterine cervix, prognosticators. histological subtype, representing up to $20 \%$ of cervical carcinoma. International Federation of Gynaecology and Obstetrics (FIGO) stage, histological grade, tumour size, lymphovascular space invasion and lymph node metastasis are major prognostic factors reported in literature (1-3). Nevertheless, additional information guiding the patient's management would be helpful. There is much interest in prognostic factors to permit more accurate patient stratification, that will improve clinical decision-making and may contribute to more rational treatment options. Current guidelines for cervical cancer recommend the same treatment regardless of histological subtype, although lower survival rates were reported for the adenocarcinoma subtype (4). Therefore increasing efforts should focus on prognosticators in adenocarcinoma of the uterine cervix.

C-Reactive protein (CRP) is widely used in clinical routine as the most important acute-phase serum protein for monitoring infection. CRP has also been shown to be elevated in patients with a variety of cancer types and an association with prognosis was found. Several studies have shown that patients with cancer have a higher level of circulating CRP than healthy controls prior to clinical diagnosis (5-8). In addition, an increase in serum CRP has been reported to be associated with poor prognosis in oesophageal, liver, colon and lung cancer (9-12). Elevated serum CRP levels have also been linked to impaired survival in patients with different gynaecological malignancies, including cervical, ovarian and endometrial cancer (13-15). However, only few studies reported on the prognostic role of CRP expression in cervical carcinoma $(14,16)$, with no data investigating exclusively the histological subtype adenocarcinoma of the uterine cervix.

The aim of the present study was to evaluate whether the pre-treatment serum CRP level might be used as a prognostic parameter in patients with adenocarcinoma of the uterine cervix and to investigate a possible correlation between the serum CRP level and various clinicopathological parameters. 


\section{Materials and Methods}

A total of 46 patients, suffering from histologically proven adenocarcinoma of the uterine cervix, treated and followed-up over a more than a 10-year period until 2015, at the Department of General Gynaecology and Gynaecologic Oncology, Medical University of Vienna, were enrolled in this retrospective study. Clinical data were obtained by chart review. Patients' charts were reviewed to obtain clinical data about age at diagnosis, histology (mucinous/endometrioid/intestinal adenocarcinoma), FIGO stage, histological grade, lymphovascular space involvement, recurrence of disease, lymph node status, pre-treatment serum CRP, cancer antigen 125 (CA 125) and carcinoembryonic antigen (CEA) levels, and time of death or loss from follow-up. Patients with insufficient data and those with secondary malignancies were excluded from this analysis. The Ethics Committee of Medical University Vienna approved the study protocol before data collection was started (EK no. 1108/2016). All patient records were anonymized and deidentified prior to analysis. Patients were staged retrospectively, according to the FIGO staging system for cervical cancer (17). All patients were treated and followed-up according to the standards of the Institution.

CRP measurements. Patients' blood was obtained before treatment by peripheral venous puncture. CRP levels were measured as a part of clinical routine by a commercially available immunotubidimetric test according to the manufacturer's instructions (Roche Diagnostics, Idianapolis, IN, USA) (18). The assay covers a range from 5 to $170 \mathrm{mg} / \mathrm{l}$ and an intra-assay variability between 1.64 and $3.34 \%$ is claimed by the manufacturer. CRP serum levels of $<5.0 \mathrm{mg} / \mathrm{l}$ are defined as normal.

Statistical analysis. Values are given as the mean (standard deviation, SD) or median (interquartile range), where appropriate. Correlation between clinicopathological parameters and serum CRP, CA 125 and CEA levels was tested using the Spearman correlation coefficient. The end-point of overall survival was used for analysis. Survival probabilities were calculated by the product limit method of Kaplan and Meier (19). Survival times of patients with no evidence of disease, with stable disease, and patients having died of non-cancer-related events were censored at the last follow-up date. Survival times of patients with cancer-related death and of patients with progressive disease at the time of last follow-up were not censored. Univariate and multivariate Cox regression models for overall survival (OS) were performed, including FIGO stage (FIGO IA vs. IB vs. II vs. III-IV), histologic grade (G1, G2 vs. G3), age at diagnosis, lymph node involvement (negative $v s$. positive), lymphovascular space involvement (negative $v s$. positive), recurrent disease and median serum CRP, CA 125 and CEA levels. $p$-Values of less than 0.05 were considered statistically significant. The SPSS system (SPSS Inc., Chicago, IL, USA) was used for these calculations.

\section{Results}

Patient characteristics. Patient characteristics, CRP levels and clinicopathological findings are given in Table I. The median age at diagnosis was 51 years (range $=24-60$ years). The 5year OS rate was $72 \%$ (95\% confidence interval $=0.582-0.89$ )
Table I. Patient characteristics, $C$-reactive protein (CRP) levels and clinicopathological findings in adenocarcinoma of the uterine cervix.

\begin{tabular}{lrcc}
\hline Parameter & $\mathrm{n}$ & $\begin{array}{c}\mathrm{CRP}, \mathrm{mean} \pm \mathrm{SD} \\
(\mathrm{mg} / \mathrm{l})\end{array}$ & $p$-Value \\
& \multicolumn{3}{c}{} \\
\hline Total numer of patients & 46 & - & - \\
Age at diagnosis & & & 0.001 \\
$\quad$ 550 Years & 20 & $2.14 \pm 3.39$ & \\
$\quad>50$ Years & 26 & $8.76 \pm 8.12$ & \\
Histology & & & 0.075 \\
$\quad$ Mucinous & 28 & $5.81 \pm 4.69$ & \\
$\quad$ Endometrioid & 16 & $6.26 \pm 10.59$ & \\
Intestinal & 2 & $3.05 \pm 3.60$ & \\
Tumor stage & & & 0.0002 \\
$\quad$ FIGO I & 9 & $3.38 \pm 8.11$ & \\
$\quad$ FIGO II & 17 & $8.86 \pm 7.18$ & \\
$\quad$ FIGO III & 7 & $3.88 \pm 2.88$ & \\
$\quad$ FIGO IV & 3 & $9.8 \pm 3.15$ & \\
Histological grade & & & 0.21 \\
$\quad$ G1 & 15 & $4.18 \pm 6.19$ & \\
$\quad$ G2 & 19 & $7.39 \pm 9.44$ & \\
$\quad$ G3 & 12 & $5.47 \pm 4.56$ & \\
Lymphovascular space involvement & & & 0.002 \\
$\quad$ No & 26 & $4.51 \pm 7.83$ & \\
$\quad$ Yes & 20 & $7.67 \pm 6$ & \\
Lymph node metastasis & & & 0.58 \\
$\quad$ Negative & 30 & $5.48 \pm 7.7$ & \\
$\quad$ Positive & 16 & $6.36 \pm 6.61$ & \\
Recurrent disease & & & 0.0001 \\
$\quad$ No & 30 & $3.07 \pm 4.92$ & \\
$\quad$ Yes & 16 & $9.68 \pm 8.25$ & \\
\hline
\end{tabular}

FIGO: International Federation of Gynecology and Obstetrics.

and $16(35 \%)$ patients showed recurrence of disease. Findings regarding surgical, irradiation and adjuvant treatment, recurrence numbers and treatment in cases of recurrence are given in Table II. The status at the last clinical observation revealed 23 patients to be alive with no evidence of disease, five with stable disease, two had progressive disease, 10 had died due to their disease and six had died due to other reasons.

Association between pre-treatment serum CRP concentration and clinicopathological parameters. The mean $( \pm \mathrm{SD})$ serum CRP level in patients with adenocarcinoma of the uterine cervix was $5.83( \pm 7.21) \mathrm{mg} / \mathrm{l}$ prior to therapy. Serum concentration of CRP correlated significantly positively with age at diagnosis $(p=0.001)$, lymphovascular space invasion $(p=0.0026)$, recurrent disease $(p=0.0001)$ and FIGO stage $(p=0.0002)$ (Table I). No significant correlation was found between serum CRP level and histology, lymph node status and histological grade $(p>0.05)$.

Univariate survival analysis revealed that advanced FIGO stage $(p=0.02)$, age $>50$ years $(p=0.03)$, recurrent disease 
Table II. Treatment and recurrence characteristics of patients with adenocarcinoma of the uterine cervix.

\begin{tabular}{lrr}
\hline & No. of cases & $\%$ \\
\hline Surgical treatment & & \\
RHE + PLND & 27 & 59 \\
Conization & 9 & 19 \\
PLND staging & 7 & 15 \\
RHE + BoR + PLND & 3 & 7 \\
Adjuvant therapy & & \\
Yes & 24 & 52 \\
RT & 20 & 43 \\
BR (sole) & 2 & 4 \\
CRT & 18 & 39 \\
CHT & 16 & 35 \\
No therapy & 22 & 48 \\
Recurrent disease and site & & \\
Yes & 16 & 35 \\
Pelvic & 6 & 13 \\
Distant & 10 & 22 \\
No & 30 & 65 \\
Treatment of recurrent disease & & \\
Yes & 11 & 24 \\
Surgery & 2 & 4 \\
RT & 4 & 9 \\
CHT & 3 & 6 \\
Combined RCHT & 2 & 4 \\
No treatment & 5 & \\
\hline & & \\
R & & \\
\hline
\end{tabular}

RHE: Radical hysterectomy; PLND: pelvic lymph node dissection; BoR: bowel resection; RT: radiotherapy; BR: brachytherapy; CRT: combined external-intracavitary irradiation; CHT: chemotherapy consisting of paclitaxel/carboplatin; RCHT: radiochemotherapy.

$(p=0.00015)$ and elevated serum CRP level $(p=0.00038)$ were associated with impaired OS (Table III). Histology, lymphovascular space involvement, histological grade and lymph node status showed no statistically significant relation to OS $(p>0.05)$.

The 5-year OS rate of patients with a pre-treatment serum CRP level $<5.0 \mathrm{mg} / \mathrm{l}$ was $100 \%$ compared with $46.9 \%$ for patients with a pre-treatment CRP level $\geq 5.0 \mathrm{mg} / \mathrm{l}$ (Figure 1). In multivariate Cox regression models with age, FIGO stage, histological grade and lymph node status, an elevated CRP level was significantly associated with shortened survival $(p=0.006)$ (Table III).

Serum CA 125 and CEA levels. The mean $( \pm \mathrm{SD})$ serum pretreatment CA 125 level was $108.8( \pm 149.12) \mathrm{mg} / \mathrm{dl}$ and correlated significantly with recurrent disease $(p=0.001)$, higher FIGO stage $(p=0.05)$, higher histological grade $(p=0.019)$ and lymphovascular space involvement $(p=0.015)$. The mean $( \pm \mathrm{SD})$ serum CEA concentration was $4.534( \pm 6.65) \mathrm{mg} / \mathrm{dl}$ prior to treatment and was significantly associated with higher histological grade $(p=0.027)$,

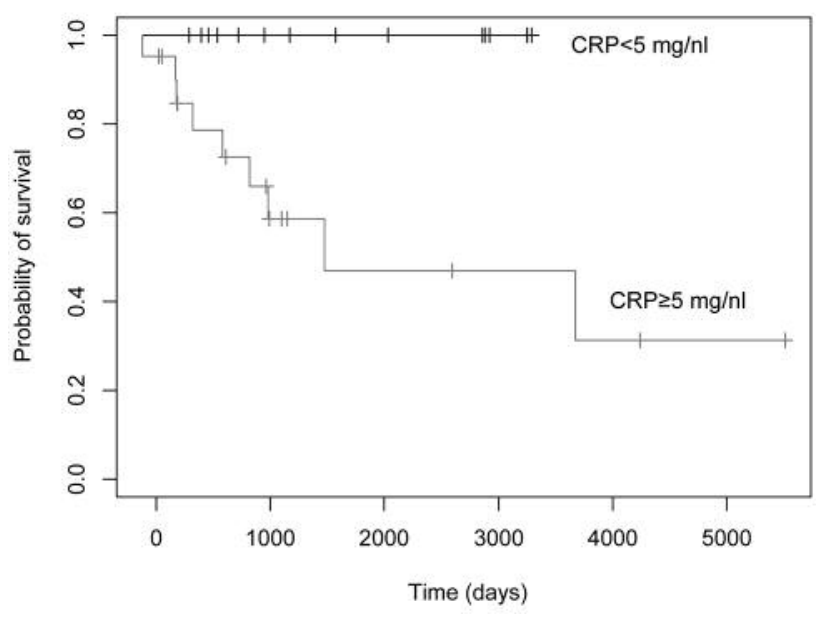

Figure 1. Kaplan-Meier analysis for overall survival in patients with adenocarcinoma of the uterine cervix, calculated according to serum $C$ reactive protein $(C R P)$ level.

recurrent disease $(p=0.0019)$ and higher FIGO stage $(p=0.04)$. Moreover, in univariate and multivariate analyses, an elevated serum CA 125 level was significantly associated with impaired overall survival $(p=0.02)$ (Table III).

\section{Discussion}

To the best of our knowledge, this is the first report to describe the pre-treatment serum CRP level as an independent prognostic parameter in a subset of patients with histologically proven adenocarcinoma of the uterine cervix. Higher serum CRP levels were found more often in patients with advanced FIGO stage, increased age, lymphovascular space invasion and recurrent disease.

In many types of human cancers, clinical decision-making is based on established clinicopathological prognosticators, which help define the individual patient's risk profile and tailor the patient's therapy accordingly.

For cervical cancer, the current guidelines recommend the same treatment regardless of histological subtype, although several studies reported lower survival rates in patients with the rare adenocarcinoma subtype (4). This might be due to less success in diagnosis and treatment of preinvasive adenocarcinoma compared to squamous cell carcinoma (20). Ongoing efforts have focused on comparing the prognosis of adenocarcinoma to squamous cell carcinoma (21), and there would seem to be a need for additional prognostic markers, especially for the histological subtype adenocarcinoma, in order to define individual patient risk.

Although cervical adenocarcinoma has lower human papillomavirus (HPV) positivity rates than squamous cell 
Table III. Univariate and multivariate survival analysis in patients with adenocarcinoma of the uterine cervix.

\begin{tabular}{lccc}
\hline Parameter & Univariate $p$-value & Multivariate HR (95\% CI) & Multivariate $p$-value \\
\hline Serum CRP & 0.000381 & $1.238(1.064-1.441)$ & 0.00557 \\
Serum CA 125 & 0.000959 & $1.012(1.002-1.022)$ & 0.0175 \\
Serum CEA & 0.024 & $1.3596(0.950-1.944)$ & 0.0922 \\
\hline
\end{tabular}

CRP: C-Reactive protein; CA 125: cancer antigen 125;CEA: carcinoembryonic antigen; HR: hazard ratio; CI: confidence interval.

carcinoma, the prevalence of HPV infection still ranges from $51-98 \%(22,23)$. Previous reports have discussed inflammation as being a critical part of tumour progression, with various inflammation-induced cytokines playing a role in cervical carcinogenesis, tumour progression and prognosis (24). To date, the prognostic value of serum CRP has been assessed in different human malignancies $(25,26)$. However, literature regarding the prognostic role of serum CRP in cervical cancer is scanty and mainly focused on squamous cell carcinoma, with no separate data existing for the subset of cervical adenocarcinoma $(14,16)$. Thus, we aimed to investigate if serum CRP could potentially serve as an additional independent prognostic marker for this histological subtype.

A series of different markers has been investigated for their capability in determining the prognosis in cervical cancer. These comprise the most common and established markers such as squamous cell carcinoma antigen, tissue polypeptide antigen, CEA and CA 12-5 (27, 28). In accordance with previous research, the present study confirmed the prognostic role of CEA and CA 12-5 in cervical adenocarcinoma $(14,27)$. Additionally, experimental inflammatory markers such as interleukin 1 , interleukin 6 and interferon $\gamma$ were found to be linked with impaired prognosis in cervical cancer (29). The disadvantage of these markers is their limited utility in the daily clinical routine due to the high costs and the need for specially equipped laboratories for their analysis.

In the present study, an elevated pre-treatment serum CRP level was strongly linked with higher FIGO stage, one of the most important prognosticators, indicating that serum CRP could act as a marker of tumour mass and tumour spread in patients with adenocarcinoma of the uterine cervix. Our findings are in line with those of Polterauer and colleagues, who in a large cohort of cervical cancer, mainly representing the squamous cell carcinoma subtype, observed that higher serum CRP levels were significantly associated with advanced tumour stage (14). A similar correlation between CRP and FIGO stage was also detected by Hefler et al. in a group of patients with epithelial ovarian cancer (13). Interestingly, in uterine leiomyosarcoma, a rare tumour of smooth muscle origin, the serum CRP level was not significantly associated with the FIGO stage (30).

In fact, high serum CRP could reflect a higher metastatic potential of the tumour, as it is known to promote metastatic spread by various mechanisms, including stimulation of angiogenesis, increase of vascular permeability and acting as an endothelial mitogen (31). This hypothesis fits our observation that higher CRP levels were also detected in patients who demonstrated recurrent disease. This knowledge might possibly be useful in the future for selecting the subgroup of patients who are at higher risk for local recurrence and metastatic spread and who could benefit from additional treatment modalities.

We further analyzed the prognostic value of CRP level prior to therapy with the Kaplan-Meier method and Cox proportional hazards regression. Serum CRP was independently associated with OS. Our data are in line with those of Polterauer and co-workers and support the role of serum CRP as independent prognostic parameter in cervical adenocarcinoma (14). The major advantage of CRP is that it is already a recognized marker of inflammation which is relatively cheap and easy to assay and is generally used in daily clinical routine in laboratories worldwide.

Our results are interesting from the clinical point of view, but we admit that at present, an elevated serum CRP level does not directly influence current treatment strategies and clinical consequences need to be determined. It is unclear if the inflammatory reaction caused by the tumour, and reflected by an increased serum CRP level, can be treated with anti-inflammatory drugs - similarly as in a trial for colorectal cancer (32) - and if this would improve prognosis. Prospective, placebo-controlled randomized trials will be necessary to clarify this issue.

We observed that the pre-treatment serum CRP level was independently associated with prognosis in patients with adenocarcinoma of the uterine cervix, possibly defining a subset of patients with impaired prognosis requiring intense therapy. We are aware of the fact that our results are limited by the relatively small number of cases and the retrospective study design, and further clinical studies with larger numbers of cases need to be performed to establish the prognostic 
value of CRP in cervical adenocarcinoma. However, if proven in future studies, serum CRP could potentially serve as a novel, easily available and relatively cheap prognostic marker in cervical adenocarcinoma, helpful in guiding therapy of these patients and define their risk profile.

\section{References}

1 Baalbergen A, Ewing-Graham PC, Hop WCJ, Striujk P and Helmerhorst TH: Prognostic factors in adenocarcinoma of the uterine cervix. Gynecol Oncol 92: 262-267, 2004.

2 Chen RJ, Chang DY, Yen ML, Fung Lee E, Huang SC, Chow SN and Hsieh CY: Prognostic factors of primary adenocarcinoma of the uterine cervix. Gynecol Oncol 69: 157164, 1998.

3 Ishikawa $\mathrm{H}$, Nakanishi $\mathrm{T}$, Inoue $\mathrm{T}$ and Kuzuya K: Prognostic factors of adenocarcinoma of the uterine cervix. Gynecol Oncol 73: 42-46, 1993.

4 Galic V, Herzog TJ, Lewin SN, Neugut Al, Burke WM, Lu YS, Hershman DL and Wright JD: Prognostic significance of adenocarcinoma histology in women with cervical cancer. Gyencol Oncol 125(2): 287-291, 2012.

5 Lundin E, Dossus L, Clendenen T, Krogh V, Grankvist K, Wulff M, Sieri S, Arslan AA, Lenner P, Berrino F, Hallmans G, Zeleniuch-Jacquotte A, Toniolo P and Lukanova A: C-reactive protein and ovarian cancer: a prospective study nested in three cohorts (Sweden, USA, Italy). Cancer Causes Control 20: 11511159, 2009.

6 Siemes C, Visser LE, Coebergrh JW, Splinter TA, Witteman JC, Uitterlinden AG, Hofman A, Pols HA and Stricker BH: Creactive protein levels, variation in the $\mathrm{C}$-reactive protein gene, and cancer risk: the Rotterdam Study. J Clin Oncol 24: 52165222, 2006.

7 Ilyassova D, Colbert LH, Harris TB, Newman AB, Bauer DC, Satterfield S and Kritchevsky SB: Circulating inflammatory markers and cancer risk in health aging and body composition cohort. Cancer Epidemol Biomarkers Prev 14: 2413-2418, 2005.

8 Trichopoulos D, Psaltopoulou T, Orfanos P, Trichopoulou A and Bofetta P: Plasma C-reactive protein and the risk of cancer: a prospective study from Greece: Cancer Epidemiol Biomarkers Prev 15: 381-384, 2006.

9 Gockel I, Dirksen K, Messow CM and Junginger T: Significance of preoperative $\mathrm{C}$-reactive protein as a parameter of the perioperative course and long-term prognosis in squamous cell carcinoma and adenocarinoma of the oesophagus. World $\mathrm{J}$ Gastroenterol 12: 3746-3750, 2006.

10 Hashimoto K, Ikeda Y, Korenaga D, Tanoue K, Hamatake M, Kawasaki K, Yamaoka T, Iwatani Y, Akazawa K and Takenaka $\mathrm{K}$ : The impact of preoperative serum $\mathrm{C}$-reactive protein on the prognosis of patients with hepatocellular carcinoma. Cancer 103: 1856-1864, 2005.

11 Mc Millan DC, Canna K and Mc Ardle CS: Systemic inflammatory response predicts survival following curative resection of colorectal cancer. Br J Surg 90: 215-219, 2003.

12 Brown DJ, Milroy R, Preston T and Mc Millan DC: The relationship between inflammation-based prognostic score (Glasgow Prognostic Score) and changes in serum biochemical variables in patients with advanced lung and gastrointestinal cancer. J Clin Pathol 60: 705-708, 2007.
13 Hefler LA, Concin N, Hofstetter G, Marth C, Mustea A, Sehouli J, Zeillinger R, Leipold H, Lass H, Grimm C, Tempfer CB and Reinthaller A: Serum C-reactive protein as independent prognostic variable in patients with ovarian cancer. Clinical Cancer Res 14(3): 710-714, 2008.

14 Polterauer S, Grimm C, Tempfer C, Sliutz G, Speiser P, Reinthaller A and Hefler LA: C-reactive protein is a prognostic parameter in patients with cervical cancer. Gynecol Oncol 107(1): 114-117, 2007.

15 Schmid M, Schneitter A, Hinterberger S, Seeber J, Reinthaller A and Hefler L: Association of elevated C-reactive protein levels with impaired prognosis in patients with surgically treated endometrial cancer. Obstet Gynecol 110(6): 1231-1236, 2007.

16 Polterauer S, Grimm C, Zeillinger R, Heinze G, Tempfer C, Reinthaller A and Hefler. Association of C-reactive protein (CRP) gene polymorphisms, serum CRP levels and cervical cancer prognosis. Anticancer Res 31: 2259-2264, 2011.

17 Lanciano RM, Won M and Hanks SE: A reappraisal of the international federation of gynecology and obstetrics staging system for cervical cancer. A study of patterns of care. Cancer 69(2): 482-487, 1992.

18 Otsuji S, Shibata $\mathrm{H}$ and Umeda M: Turbidimetric immunoassay of serum C-reactive protein. Clin Chem 28: 2121-2124, 1982.

19 Kaplan EL and Meier P: Nonparametric estimation from incomplete observations. Am J Stat Assoc 53: 457-481, 1958.

20 Berrington de Gonzalez: International Collaboration of Epidemiological Studies of Cervical Cancer. Comparison of risk factors for invasive squamous cell carcinoma and adenocarcinoma of the cervix: collaboration reanalysis of individual data on 8,097 women with squamous cell carcinoma and 1,374 women with adenocarcinoma from 12 epidemiological studies. Int J Cancer 120(4): 885-891, 2007.

21 Lee JY, Kim YT, Kim S, Lee B, Lim MC, Kim JW and Won YJ: Prognosis of cervical cancer in the era of concurrent chemoradiation from National database in Korea: A comparison between squamous cell carcinoma and adenocarcinoma. PLoS ONE 10(2): e0144887, 2015.

22 de Sanjose S, Quint WG, Alemany L, Geraets DT, Klaustermeier JE, Lloveras B, Tous S, Felix A, Bravo LE, Shin HR, Vallejos CS, de Ruiz PA, Lima MA, Guimera N, Clavero O, Alejo M, Llombart-Bosch A, Cheng-Yang C, Tatti SA, Kasamatsu E, Iljazovic E, Odida M, Prado R, Seoud M, Grce M, Usubutun A, Jain A, Suarez GA, Lombardi LE, Banjo A, Menéndez C, Domingo EJ, Velasco J, Nessa A, Chichareon SC, Qiao YL, Lerma E, Garland SM, Sasagawa T, Ferrera A, Hammouda D, Mariani L, Pelayo A, Steiner I, Oliva E, Meijer CJ, Al-Jassar WF, Cruz E, Wright TC, Puras A, Llave CL, Tzardi M, Agorastos T, Garcia-Barriola V, Clavel C, Ordi J, Andújar M, Castellsagué X, Sánchez GI, Nowakowski AM, Bornstein J, Muñoz $\mathrm{N}$ and Bosch FX: Human papillomavirus genotype attribution in invasive cervical cancer: a retrospective tive crosssectional worldwide study. Lancet Oncol 11: 1048-1056, 2010.

23 Nagai Y, Maehama T, Asato T and Kanazawa K: Detection of human papillomavirus DNA in primary and metastatic lesions of carcinoma of the cervix in women from Okinawa, Japan. Am J Clin Oncol 24: 160-166, 2001.

24 Schacter E and Weitzman SA: Chronic inflammation and Cancer. Oncology 16: 217-226, 2002.

25 Zahlten-Hinguranage A, Goldschmidt H, Cremer FW, Egerer G, Moehler T, Witte D, Bernd L, Sabo D and Zeifang F: 
Preoperative elevation of serum C-reactive protein is predictive for prognosis in myeloma bone disease after surgery. $\mathrm{Br} \mathrm{J}$ Cancer 95: 782-787, 2006.

26 Guillem P and Triboulet JP: Elevated serum levels of C-reactive protein are indicative of poor prognsosis in patients with esophageal cancer. Dis Esophagus 18: 146-150, 2005.

27 Gocze PM, Vahrson HW and Freeman DA: Serum levels of squamous cell carcinoma antigen and ovarian carcinoma antigen (CA 125) in patients with benign and malignant diseases of the uterine cervix. Oncology 51: 430-434, 1994.

28 Gaarenstroom KN, Kenter GG, Bonfrer JM, Korse CM, Van de Vijver MJ, Fleuren GJ and Trimbos JB: Can initial serum cyfra 21-1, SCC antigen, and TPA levels in squamous cell cervical cancer predict lymph node metastases or prognosis? Gynecol Oncol 77: 164-170, 2000.

29 Fujiwaki R, Iida K, Nakayama K, Kanasaki H, Hata K and Katabuchi $\mathrm{H}$ et al: Clinical significance of interleukin-1 receptor antagonist in patients with cervical carcinoma. Gynecol Oncol 89: 77-83, 2003.
30 Schwameis R, Grimm C, Petru E, Natter C, Staudigl C, Lamm W, Koelbl H, Krainer M, Brodowicz T, Reinthaller A and Polterauer S: The prognostic value of C-reactive protein serum levels in patients with uterine leiomyosarcoma. PLoS ONE. 10(8): $\mathrm{e} 0133838,2015$.

31 Eberhard OK, Langefeld I, Kuse ER, Brunkhorst FM, Kliem V, Schlitt HJ, Pichlmayr R, Koch KM and Brunkhorst R: Procalcitonin in the early phase after renal transplantation-Will it add to diagnostic accuracy? Clin Transplant 12: 206-211, 1998.

32 Ye XF, Wang J, Shi WT, He J and He J: Relationship between aspirin use after diagnosis of colorectal cancer and patient survival: a meta-anaylsis of observational studies. Br J Cancer 111(11): 2172-2179, 2014.
Received July 28, 2016

Revised August 9, 2016

Accepted August 18, 2016 